\title{
O estágio no contexto da formação de professores: campo de experimentação e reflexão sobre a prática pedagógica
}

Ângela Maria Hartmann angelahart2010@gmail.com 0000-0002-4028-8577 Universidade Federal do Pampa Caçapava do Sul, Rio Grande do Sul, Brasil.

Mara Elisângela Jappe Goi maragoi28@gmail.com 0000-0002-4164-4449

Universidade Federal do Pampa, Caçapava do Sul, Rio Grande do Sul, Brasil.

\author{
RESUMO
}

Relata-se o resultado da investigação sobre a experiência de introduzir o estágio docente no curso de Ciências Exatas - Licenciatura, da Universidade Federal do Pampa (UNIPAMPA), campus Caçapava do Sul/RS a partir do terceiro semestre do Curso. Nessa perspectiva, o formato de estágio assume a característica de ser um espaço interdisciplinar que oportuniza ao graduando conhecer o ambiente profissional por meio de atividades didáticopedagógicas de observação, problematização e reflexão da prática docente. A questão que norteia a discussão é: Em que aspectos as mudanças introduzidas nos estágios melhoraram a formação dos acadêmicos e demandam novos desafios aos docentes orientadores? Para tal, analisam-se as práticas de estágio implementadas a partir da alteração do Projeto Pedagógico do Curso. Apresentam-se resultados plenamente favoráveis para que a prática docente ocorra desde os primeiros anos de graduação, como uma ação integrada a outros componentes curriculares e não apenas como um complemento pedagógico no final da graduação.
\end{abstract}

PALAVRAS-CHAVE: Estágio de docência. Prática pedagógica. Formação de professores. Licenciatura. 


\section{INTRODUÇÃO}

O estágio curricular supervisionado obrigatório nos cursos de licenciatura tem como objetivo estabelecer uma relação entre a teoria e a prática, tal como expressa o art. 1으, parágrafo $2^{\circ}$ e o art. 3ำ, inciso XI, da Lei de Diretrizes e Bases da Educação Nacional (LDBEM no 9394/96) (BRASIL, 1996), de dezembro de 1996. Nesse contexto, deve estar presente tanto nos momentos em "que se trabalha na reflexão sobre a atividade profissional, como durante o estágio, nos momentos em que se exercita a atividade profissional" (BRASIL, 2001, p. 23). Assim, o estágio é um componente curricular, de caráter teórico-prático obrigatório que proporciona ao acadêmico o contato com o contexto escolar, acompanhado pela instituição formadora. Por esse motivo, configura-se em uma atividade privilegiada de diálogo crítico com a realidade que favorece a articulação ensino, pesquisa e extensão.

Por outro lado, entende-se que o estágio de docência constitui-se como campo de conhecimento. Por essa razão, é atribuído a ele um estatuto epistemológico que supera sua tradicional redução à prática instrumental. Nesse sentido, as práticas educativas de estágio podem incluir atividades de pesquisa (PIMENTA; LIMA, 2005, 2006). Assim, defende-se que o estágio, além de fazer parte da formação de futuros professores, constitui-se como um campo de pesquisa a ser explorado.

Centrado na formação inicial, o estágio de docência é uma etapa da formação em que o licenciado explora o repertório da prática pedagógica e abarca as principais vivências e percepções associadas ao "tornar-se-professor", conhecendo ganhos e dificuldades inerentes a este processo. Simões (1996) argumenta que o estágio é um período significativo na vida pessoal e profissional do professor. Assim, o estágio se constitui por momentos formativos em que o futuro professor constrói competências e conhecimentos, como também desenvolve a sua capacidade de avaliação profissional.

Pimenta e Lima $(2005,2006)$ destacam que em diversas profissões se aprende através de imitação de modelos, no sentido de fazer algo ou promover uma ação. Para as autoras, o futuro professor aprende por imitação, observação, reprodução de modelos considerados bons, porém esse aprendizado pode apresentar limitações. A formação do professor, quando se dá pela observação e reprodução de modelos, não valoriza a formação individual, reduzindo à atividade docente apenas a um fazer pedagógico. Assim, o estágio quando imita determinados modelos não faz análise crítica da realidade social em que o ensino se processa, não leva em consideração a realidade do indivíduo e tampouco está preocupado com a sua formação intelectual (PIMENTA; LIMA, 2005, 2006). O estágio, nessa perspectiva, não é sinônimo de aplicação de técnicas. A prática pela prática e o emprego de técnicas sem a devida reflexão pode reforçar a ilusão de que há uma prática sem teoria e vice-versa (PIMENTA; LIMA, 2005, 2006). Desse modo, muitas vezes o estágio fica reduzido ao momento da prática, ao como fazer e quais as melhores técnicas utilizar.

Considera-se que o estágio necessita ser o momento de fortalecer a teoria e a prática, em que o futuro docente visualiza a prática como ação e reflexão. A ação se refere aos sujeitos, seu modo de agir, pensar, seus valores, seu modo de ensinar, de relacionar, de ver o mundo e de planejar. Desse modo, se o objetivo do estágio 
Os cursos de licenciatura vêm incorporando ao longo dos semestres práticas pedagógicas que visam promover a articulação entre teoria e prática, propiciando uma discussão contínua entre o saber e o fazer. Dessa maneira, o futuro professor é orientado a buscar significados para o trabalho de gestão do ensino, além de capacitar-se para a resolução de diversas situações-problema relacionadas ao contexto escolar. Nesse sentido, defende-se que a prática e a teoria pedagógicas sejam estudadas, trabalhadas e articuladas desde os primeiros semestres da licenciatura, incluindo-as, inclusive, em componentes curriculares técnicocientíficos. Por meio de práticas pedagógicas inseridas em diversos componentes curriculares pedagógicos e técnico-científicos, estimula-se que o licenciado planeje, gerencie e exercite atividades de ensino sobre conteúdos científicos estudados no curso de graduação.

Como forma de promover uma vivência mais próxima do campo profissional, as quatrocentas (400) horas relativas ao estágio curricular do curso de Ciências Exatas - Licenciatura (CCEL) da Universidade Federal do Pampa (UNIPAMPA), do campus Caçapava do Sul/RS, estão distribuídas ao longo dos seis últimos semestres, de um total de oito semestres. Desde 2015 (UNIPAMPA, 2013), a partir da alteração do Projeto Pedagógico do Curso (PPC), o estágio acontece do terceiro ao oitavo semestres, ao invés de apenas nos últimos três (sexto ao oitavo semestres), como acontecia até então, conforme previa o PPC do curso de 2011 (UNIPAMPA, 2011). Tendo em vista esse contexto, a questão investigativa desse artigo é discutir em que aspectos as mudanças introduzidas no estágio curricular supervisionado tornaram a formação dos acadêmicos mais adequada e demandaram novos desafios aos docentes orientadores?

Para tal, analisam-se as práticas de estágio implementadas a partir da alteração do PPC do CCEL, em 2015, comparando-as com as vigentes até então, destacando as razões para promover essas modificações, os ajustes necessários para uma formação inicial melhor qualificada e a evolução profissional dos docentes para o atendimento de exigências atuais de formação docente.

\section{ESTÁGIO DOCENTE: PROPOSTA DE SUPERAÇÃO DA DICOTOMIA TEORIA E PRÁTICA}

O estágio de docência por muitos anos passou a ser a culminância dos cursos de formação inicial de professores, sendo o primeiro momento de contato direto dos licenciandos com o contexto de sala de aula (BRITZMAN, 1991; MACHADO, 1996; SIMÕES, 1996; CAPEL; LEASK; TURNER, 1997; CAIRES; ALMEIDA, 2001). Delineia-se, contudo, uma nova concepção de prática, como uma dimensão de conhecimento que se faz presente nos diversos momentos de formação e que se reflete na atividade profissional. O estágio, nesse sentido, vem passando por mudanças nas universidades brasileiras.

As mudanças curriculares do Ensino Superior, que visam superar os modelos desarticulados de formação inicial de professores da Educação Básica em cursos de nível superior (estruturados em um sistema curricular conhecido como " $3+1$ "), orientam para que a prática docente ocorra ao longo do curso de formação, desde o primeiro ano como uma ação integrada e não apenas como um apêndice no final da graduação. O Parecer CNE/CP9/2001 possibilita que as horas de estágio curricular sejam diluídas pelos vários semestres do curso de licenciatura, o que 
permite ao licenciando um contato acadêmico formal com o ambiente escolar mais cedo, favorecendo o seu processo de profissionalização (ANDRADE; RESENDE, 2010).

Desse modo, o estágio é um espaço formativo e de sensibilização dos graduandos para o atendimento das necessidades sociais, atentos aos valores éticos que podem orientar a prática profissional. É um momento de aproximação e compreensão da realidade profissional favorecendo a reflexão sobre a realidade e a aquisição da autonomia intelectual e o desenvolvimento de habilidades conexas à profissão docente (UNIPAMPA, 2014).

O estágio de docência do CCEL está fundamentado nos seguintes objetivos:

\begin{abstract}
Articular ensino, pesquisa e extensão; proporcionar ao estagiário a reflexão teórico-crítica sobre os conteúdos e procedimentos teórico-metodológicos do período de formação inicial com os domínios da prática (CNE/CP 2001); promover o processo de integração entre Universidade e as escolas de Educação Básica;

promover a interdisciplinaridade;

estimular a prática da pesquisa como princípio da formação inicial e permanente do professor das áreas de Ciências Exatas e da Terra; favorecer, no período de formação, a reflexão sobre as dificuldades, limites e desafios próprios da profissão docente na Educação Básica e, colocar o estagiário em contato com a rotina escolar, incluindo as dimensões pedagógicas, administrativas e políticas. (UNIPAMPA, 2014, p. 46).
\end{abstract}

Para a realização dos estágios docentes, é necessária a construção de projetos avaliados conjuntamente pela escola e pela universidade. Essas duas instâncias assumem a responsabilidade de auxiliar-se mutuamente na orientação e supervisão dos estagiários, o que pressupõe relações formais entre instituições de ensino e unidade do sistema de ensino (CNE/CP27/2001). Assim, os estágios são realizados na Educação Básica em escolas da rede oficial de ensino, preferencialmente em escolas públicas, ou em espaços educativos, mediante convênios institucionais e o coordenador dos estágios é o responsável por firmar os convênios com as instituições e cadastrar os locais de estágio.

Os estágios no CCEL começaram a ser realizados em 2011, quando os primeiros licenciandos alcançaram o sexto semestre do curso, depois de cinco semestres em que cursavam apenas alguns componentes curriculares que contemplavam horas de prática pedagógica. Os três semestres com estágios curriculares eram distribuídos da seguinte forma: 60 semestre: 60 horas de estágio de observação; 70 semestre: 180 horas de estágio de monitoria, formação de grupos de estudos orientados (GEO) e regência; 8 o semestre: (mais) 180 horas de estágio de monitoria, formação de grupos de estudos orientados (GEO) e regência.

Essa estrutura de oferta de estágios perdurou por quatro anos (2011 a 2014). A partir de 2015, com a implantação de nova matriz curricular, o estágio curricular passou a acontecer nos componentes que recebem o nome geral de "Cotidiano da Escola", acompanhado de um complemento que as diferencia. Os estágios curriculares são distribuídos, desde então, nos seguintes componentes curriculares: 3ㅇ semestre: 60h - Cotidiano da Escola: observação; 40 semestre: 60hCotidiano da Escola: observação e intervenção; 5o semestre: 60h- Cotidiano da Escola: Monitoria; 6o semestre: 60h- Cotidiano da Escola: Grupos de Estudos Orientados - GEO; 7o semestre: 80h- Cotidiano da Escola: Regência I e no 8o semestre: 80h- Cotidiano da Escola: Regência II. 
O estágio de Cotidiano da Escola: Observação, realizado no 3ㅇ semestre tem como objetivos: i) reconhecer e problematizar a realidade escolar e da sala de aula; ii) utilizar instrumentos de coleta de dados com a finalidade de evidenciar a concepção de escola do graduando e do professor de Educação Básica; iii) promover a ambientalização e análise crítica de diferentes espaços escolares.

No 4 o semestre há um componente curricular de 60h denominado Cotidiano da Escola: observação e intervenção. Este estágio tem como objetivos: i) investigar as condições para a experimentação docente no ensino de Ciências Exatas e da Terra, ou seja, se existem interações sociais que tornem os conceitos e as explicações científicas mais acessíveis e eficientes; ii) utilizar de instrumentos de coleta de dados com a finalidade de evidenciar a concepção do graduando sobre a sala de aula ou outros espaços-ambiente enquanto lugares de experimentação da docência e intervenção, bem como a visão do professor e a investigação das possibilidades do próprio processo pedagógico enquanto experimentação; iii) promover a ambientalização e a análise crítica sobre outros espaços escolares, socialização e discussão das experiências vivenciadas por estudantes bolsistas do Programa Institucional de Bolsa de Iniciação à Docência (PIBID), uma vez que se consideram as intervenções realizadas a partir do PIBID como significativos espaços para o reconhecimento e a ambientalização do contexto da escola básica pelos acadêmicos.

Seguindo ao 5 o semestre o componente curricular de $60 \mathrm{~h}$ denominado Cotidiano da Escola: Monitoria tem por objetivo: i) inserir os licenciandos na elaboração de atividades de complementação das aulas desenvolvidas pelo professor supervisor (aulas de monitoria); ii) interagir com os estudantes da Educação Básica que apresentam dificuldades no processo de ensino e aprendizagem, de modo a ter um contato mais intenso com os desafios presentes no contexto escolar.

No 6o semestre: 60h - Cotidiano da Escola: Grupos de Estudos Orientados GEO, é realizado a partir do desenvolvimento de atividades relacionadas a uma temática que permita contextualizar os conhecimentos específicos dos componentes curriculares do CCEL. Os licenciandos elaboram uma proposta didático-pedagógica que procura articular o conhecimento cotidiano e o conhecimento científico, buscando diversas estratégias para significação do conteúdo escolar.

No 70 semestre acontece o estágio de 80h - Cotidiano da Escola: Regência I. Nesse componente há diversas atividades desenvolvidas pelos graduandos como: planejamento da atividade prática docente, registros reflexivos, reuniões pedagógicas, orientações individuais e coletivas, avaliação e reflexão da ação na vivência do processo, relato e análise da ação educativa vivenciada no estágio realizado na Educação Básica, teorização de temáticas implicadas na prática pedagógica, elaboração de proposições educacionais para os conflitos inerentes à ação docente.

Finalizando os estágios no 8 o semestre ocorre o estágio de 80h - Cotidiano da Escola: Regência II, em que acontece o planejamento da atividade prática docente, registros reflexivos, reuniões pedagógicas, orientações individuais e coletivas, avaliação e reflexão da ação na vivência do processo, relato e análise da ação educativa vivenciada no estágio realizado na Educação Básica, teorização de 
temáticas implicadas na prática pedagógica, elaboração de proposições educacionais para os conflitos inerentes à ação docente.

Um dos produtos dos componentes curriculares de estágio de 3 ㅇ e 4응 semestres (Cotidiano da Escola: observação e Cotidiano da Escola: observação e intervenção), é um relatório analítico-reflexivo sobre a observação e a vivência da prática docente na escola ou em espaços não formais de educação. O produto do estágio curricular do 5o semestre (Cotidiano da Escola: monitoria) inclui um relatório contendo o plano de atividades, bem como uma reflexão sobre a prática de ensino vivenciada. O produto do estágio do 6o semestre (Cotidiano da Escola: GEO) é um projeto de ensino, contendo a justificativa, a metodologia empregada, o plano de atividades e reflexões sobre a ação praticada. Já, o produto dos estágios curriculares que compreendem o 7으 e 8을 semestres (Cotidiano da Escola: Regência I e Cotidiano da Escola: Regência II) é um relatório ou artigo científico analíticoreflexivo sobre a vivência da prática docente na escola.

Esse novo formato de estágios, além de superar o modelo " $3+1$ ", adota um modelo que, segundo Andrade e Resende (2010), assume a característica de ser um espaço interdisciplinar que oportuniza ao graduando conhecer o ambiente de trabalho, por meio de atividades didático-pedagógicas de observação, problematização e reflexão da prática docente. Assim, o estágio curricular é um dos componentes que favorece a ação-reflexão-ação sob a orientação de um professor mais experiente (CAPORALE, 2015).

Espera-se que os licenciados ao participarem de atividades com professores mais experientes, tornem-se professores da Educação Básica, ou do Ensino superior, ou mesmo profissionais em espaços educativos não formais, capazes de discutir questões fundamentais sobre currículo escolar, planejamento pedagógico, aspectos políticos e culturais da realidade escolar (SANTOS; PASSOS, 2008).

\section{MUDANÇAS NO ESTÁGIO CURRICULAR: MOTIVAÇÕES E RESULTADOS}

A primeira alteração no estágio curricular foi a distribuição das quatrocentas (400) horas ao longo de seis semestres do curso ao invés de apenas três. Na sequência, outras foram acontecendo como a introdução da pesquisa em atividades dos componentes curriculares de estágio, a exploração de espaços não formais de educação para as práticas educativas, o acompanhamento do trabalho dos professores supervisores por meio da monitoria em sala de aula da Educação Básica, a elaboração e desenvolvimento de projetos interdisciplinares em aulas de Seminário Integrado no Ensino Médio, a escrita reflexiva em textos que, aos poucos, deixaram de ser relatórios para se apresentarem como artigos acadêmicos.

A seguir discute-se mais detalhadamente cada um desses desdobramentos do estágio, descrevendo as motivações para as mudanças e os resultados obtidos a partir de cada uma delas. Ressalta-se que as motivações para as mudanças são resultado de aprendizado dos professores orientadores de estágio sobre, essencialmente, o que contribui para a formação profissional dos licenciandos. Porém, também existiu uma preocupação com a melhoria do trabalho em sala de aula da Educação Básica, contribuindo, de alguma forma, com o trabalho dos professores supervisores de estágio. 
A sensibilização em relação aos desafios da docência na Educação Básica foi, em grande parte, gerada pelas parcerias construídas entre docentes pelo Programa de Bolsa de Iniciação à Docência (PIBID). É importante ressaltar que praticamente todos os professores da educação superior - atuantes no estágio têm ou tiveram experiência com a coordenação de grupos de pibidianos. De um modo geral, situação semelhante se verificou com os professores supervisores de estágio nas escolas. Boa parte deles é (ou já foi) supervisor do PIBID. Essa parceria prévia ao estágio proporciona aos docentes uma maior capacidade de perceber os aspectos que representam dificuldades, incertezas e inseguranças para os estagiários e permitiu colocar em ação soluções antecipadas.

\section{A DISTRIBUIÇÃO DA CARGA HORÁRIA DE ESTÁGIO}

O CCEL da UNIPAMPA, Caçapava do Sul, RS, iniciou em 2009, tendo definida pouco mais de cinquenta por cento de sua matriz curricular. Nessa primeira metade estavam concentrados componentes curriculares específicos de cada área de formação (Física, Química e Matemática) e também alguns da área de formação pedagógica como Fundamentos da Educação, Políticas Públicas, Psicologia e Educação, além de outros quatro componentes, que concentravam as atividades de prática pedagógica, denominadas de Instrumentação para o Ensino de Ciências (A, B, C e D). Os estágios curriculares eram previstos para o final do curso, ainda num formato que lembrava o " $3+1$ " das antigas licenciaturas. Mesmo tentando evitar o acúmulo de horas, o estágio ficou concentrado nos três últimos semestres, sendo que o sétimo e oitavo concentravam cento e oitenta horas de estágio em cada um. Esses dois semestres de estágio eram precedidos de um estágio de observação de sessenta horas em que os licenciandos faziam um mapeamento das escolas onde, nos dois semestres seguintes, realizariam o estágio de regência.

A carga horária reservada para os dois estágios de regência era relativamente grande, pensou-se em aproveitar parte das cento e oitenta horas para os licenciandos realizarem outras duas atividades: i) aulas de reforço em turno diferente ao turno em que realizavam as aulas de regência; e ii) formar um Grupo de Estudos Orientados (GEO) para o desenvolvimento de uma proposta de estudo aprofundada em algum tópico da área de formação do licenciando. Assim, além de vinte horas de regência, os acadêmicos cumpriam vinte horas de estágio com aulas de reforço e vinte horas com o desenvolvimento de um GEO. As demais cento e vinte horas eram destinadas à participação em encontros de orientação, ao planejamento das atividades e a produção de um relatório documentando as ações desenvolvidas.

Apesar de sessenta horas em cento e oitenta horas (33\% das horas de estágio) parecer ser um tempo razoável para o desenvolvimento de atividades nas escolas, os resultados negativos e as críticas por parte dos licenciandos começaram a acontecer já no final da primeira experiência. Desenvolver três atividades diferentes em um mesmo componente de estágio demandava muito tempo de planejamento dos licenciandos. Primeiro, eles tinham outros componentes curriculares para cursar durante o semestre e, segundo, eles não conseguiam se organizar a tempo de realizar essas atividades de forma concomitante durante o semestre letivo. Eles solicitavam que fosse realizada uma atividade para depois se dedicar a outra. Com isso, um semestre letivo se tornava pouco tempo para desenvolver todas as atividades pertinentes ao estágio. A essa dificuldade dos 
estagiários, somavam-se as paralisações de docentes e períodos destinados a comemorações pelas escolas (Páscoa, Gincana do Estudante, Jogos Estudantis, Semana da Pátria, Semana Farroupilha, Aniversário da Cidade etc.), o que tornava um semestre letivo um período curto para a realização das três atividades em sequência.

A primeira modificação, nesses dois semestres de estágio de cento e oitenta horas cada um, foi concentrar em um deles as horas de aula de reforço e de GEO e no outro as aulas de regência. Essa nova organização permitiu que os estagiários realizassem com maior tranquilidade esses dois estágios. Entretanto, percebia-se que ainda havia uma subutilização das horas destinadas ao estágio, pois eles dedicavam às horas de planejamento das atividades e de escrita dos relatórios, que não eram presenciais, para realizar tarefas de outros componentes curriculares. Por outro lado, as horas presenciais para leituras e discussões sobre a formação docente através do estágio eram dedicadas quase que exclusivamente para orientação de procedimentos a serem adotados na escola ou preparação de atividades. Os estagiários pouco liam ou refletiam teoricamente sobre o estágio.

Os docentes do CCEL viram, em 2013, durante a alteração do PPC, a oportunidade de propor a distribuição da carga horária de estágio de forma mais equitativa ao longo dos semestres. Assim, além de uma nova distribuição das horas, as atividades de estágio também foram melhores distribuídas. Foram criados seis períodos de estágio, sendo o primeiro já no terceiro semestre do curso. Para alguns professores, parecia ser prematuro começar o estágio tão cedo, mas a experiência do PIBID mostrava que era possível introduzir os licenciandos nas escolas mesmo eles estando no início do curso.

Essa nova organização do estágio acabou criando outra dificuldade: o grande número de licenciandos circulando pelas duas das escolas com Ensino Médio no centro urbano do município. Como havia, nessas duas escolas, licenciandos de vários semestres realizando estágio (além dos pibidianos com atividades próprias), foi necessário criar possibilidades de estágio também nas escolas rurais, afastadas do centro urbano do município. Como consequência, surgiram novos problemas, como o de transporte para essas escolas, mas que, aos poucos, foram contornados por docentes e estagiários.

A avaliação que os licenciandos fazem da nova estruturação do estágio é positiva. O tempo de estágio é melhor aproveitado para leituras, reflexões, pesquisas e atuação nas escolas. Também está mais bem caracterizado o que o licenciando deve fazer em cada semestre de estágio.

\section{A PESQUISA COMO PRÁTICA PEDAGÓGICA NO ESTÁGIO CURRICULAR}

Os docentes, a partir da nova estruturação da matriz curricular, intensificaram a exigência da pesquisa como uma das atividades de estágio. Concordando com a concepção de que envolver os licenciandos em processos investigativos sobre o ensino e a aprendizagem na escola é um objetivo importante para formar, na área de Ciências e Matemática, professores produtores de conhecimento e não meros transmissores (CARVALHO, 2012), os docentes orientadores incentivam os estagiários a realizar pesquisas durante cada um dos estágios. $O$ tipo de pesquisa varia de acordo com o tipo de estágio. Cita-se aqui o exemplo do estágio Cotidiano da Escola: observação e intervenção. 
Com o objetivo de "oportunizar ao aluno o reconhecimento da realidade escolar, promovendo um espaço de problematização e reflexão das diferentes dimensões que interferem no fazer docente" (UNIPAMPA, 2014, p. 105), propôsse aos quinze acadêmicos em estágio, que realizassem, em duplas ou trios, as seguintes pesquisas:

- Pesquisa em portais do Ministério da Educação sobre as propostas de programas e ações do governo federal voltados para a Educação Básica, tais como Mais Educação, Escola Aberta, Implantação de salas de Recursos Multifuncionais, Pacto para o Fortalecimento do Ensino Médio, etc., seguida de apresentação aos colegas de turma.

- Pesquisa sobre como é realizada a implantação desses programas em escolas do município e a redação de um artigo a respeito, além da apresentação dos resultados aos colegas durante as aulas presenciais.

- Pesquisa sobre as atividades educativas realizadas em espaços não formais de educação, tais como: Biblioteca Pública Municipal, Museu Municipal de Cultura, Comissão de Educação da Câmara de Vereadores, Secretaria Municipal de Educação, Ponto de Cultura, Serviço Nacional do Comércio etc.

As atividades basearam-se no princípio do educar pela pesquisa, proposta em obras do sociólogo Pedro Demo (2004, 2007, 2009). Educar pela pesquisa tem por objetivo superar o aprender por repetição e capacitar o estudante a buscar informações para formular conhecimento próprio, pois: "O ato de pesquisa permite ao aluno se transformar em agente da própria aprendizagem" (ROSA, 2008 , p. 213), a elaborar por si mesmo o conhecimento que lhe pode ser útil na academia e na vida profissional.

A realização das visitas às escolas e aos espaços não formais, a realização de entrevistas com pessoas responsáveis pela execução dos programas ou atividades voltadas para a educação, bem como a apresentação aos colegas das informações levantadas, possibilitou uma discussão/reflexão fundamentada na teoria e na prática. A escrita de artigos, relatando os resultados da pesquisa, exige dos estagiários tornar claros os resultados das suas investigações.

A investigação sobre como são implantados os programas do governo federal nas escolas contribui para que os estagiários compreendam melhor as políticas públicas para a Educação Básica e aguça seu senso crítico em relação à execução dos programas nas escolas do município. Essa reflexão crítica acentua seu senso de responsabilidade em relação ao futuro da educação no município, e no país, contribuindo para seu amadurecimento pessoal e profissional.

Para os docentes do Curso, ficou claro que a oferta de um componente nos moldes desse estágio foi importante para a retomada de temáticas/conteúdos estudados em outros componentes curriculares do curso, tais como "Políticas Públicas no Contexto Brasileiro", "Educação Inclusiva", "Organização Escolar e Trabalho Docente", promovendo a reflexão teórica e crítica sobre conteúdos e procedimentos teórico-metodológicos da formação inicial e os domínios da prática. 


\section{A ESCRITA REFLEXIVA COMO PRÁTICA PEDAGÓGICA NO ESTÁGIO}

Nos primeiros estágios (2012 e 2013), os docentes centravam-se em solicitar, como produto final para avaliação, a apresentação de um relatório em que os licenciandos documentavam as atividades de estágio. Aos poucos, com a experiência de apresentação de trabalhos em eventos, percebeu-se que seria mais produtivo se os estagiários aproveitassem seus relatos para produção de artigos acadêmicos.

Os acadêmicos, de um modo geral, são bastante eloquentes e têm facilidade em expor seu pensamento, mas inibem-se quando se trata de apresentá-lo por escrito. Produzir um texto, mesmo que um parágrafo, não é tarefa fácil para estudantes não habituados a apresentar suas concepções e reflexões por escrito. Diferente da fala, na qual o conteúdo do pensamento é explicitado entre o agente expositor e o receptor no mesmo espaço-tempo, na escrita não acontece essa facilidade. $O$ texto necessita ser tão claro que seja capaz de bastar-se, pois não é possível intervir buscando maiores esclarecimentos (BIANCHETTI, 2012).

Os docentes da licenciatura também constatam, por parte de vários acadêmicos, uma grande dificuldade em produzir um texto de autoria. A elaboração própria, como parceira da pesquisa, desafia o aluno a 'fazer' conhecimento e "não apenas escutar, reproduzir, repassar" (DEMO, 2004, p. 18). Elaborar um texto próprio desenvolve a habilidade de pensar com lógica, coerência e consistência, além da capacidade de argumentar em profundidade. Os licenciandos costumam dizer que é difícil colocar "nas próprias palavras" o que leem, pois não se sentem preparados para contestar as ideias dos autores ou elas Ihes parecem tão bem escritas que não lhes é possível dizer de modo diferente. Acontece a denominada "mistificação do autor" (BIANCHETTI, 2012), como se bons textos fossem produções de pesquisadores que não necessitam de exaustivo processo de aprimoramento dos seus escritos.

Assim sendo, é detectado um número considerável de "plágios" nos seus textos, pois na falta do que dizer ou para conseguir introduzir em sua escrita algo teórico, os licenciandos acabam copiando trechos de suas leituras. Para contornar essa dificuldade, os docentes têm estimulado os licenciandos a produzir resenhas ou produzir breves comentários escritos sobre leituras agendadas para discussão nos encontros semanais de estágio.

Outra dificuldade é a apresentação de um texto com clareza e coesão. É comum encontrar, na escrita dos acadêmicos, frases com sentido incompleto ou ambíguo e repetição de ideias alguns parágrafos adiante. Para contornar essa dificuldade, os docentes aprenderam que é interessante orientar o licenciando a deixar o texto "em repouso" por pelo menos um dia para, então, retomar sua leitura e revisão antes de disponibilizá-lo ao professor. Os próprios licenciandos acabam por perceber que sua escrita tem problemas e pode ser melhorada.

$O$ incentivo à escrita de resumos para submissão em eventos, como o Salão Internacional de Ensino, Pesquisa e Extensão (SIEPE), evento anual da UNIPAMPA e outros eventos da área (Encontro de debates de Ensino de Química-EDEQ, Seminário Internacional de Educação em Ciências- SINTEC), Encontro Nacional de pesquisadores em Educação em Ciências (ENEPEC), Escola de Inverno de Educação Matemática, também contribuíram para a motivação dos licenciandos para a escrita. A possibilidade do resumo ou trabalho ser apresentado em um evento 
concretiza a possibilidade de alguém mais ler o texto, além do professor que irá avaliá-lo, é uma motivação para uma escrita bem feita. Como afirma Bianchetti (2012), citando Umberto Eco, só se escreve para um leitor e mente quem diz que escreve para si mesmo.

É possível constatar que, à medida que os licenciandos vão avançando no curso, sua escrita melhora bastante e são produzidos excelentes artigos como resultados do estágio. Isso sinaliza que a dificuldade está sendo superada, pois vários dos graduandos estão apresentando os produtos de seus estágios em eventos da área (AZAMBUJA, GOI, HARTMANN, 2014; GOI, AZAMBUJA, 2014; CONRADO, GOI, 2015; VIVIAN, VIVIAN, GOI, 2015; HIRATA GOI, 2015; VIVIAN, HARTMANN, VIVIAN, 2015; BRASIL, SIQUEIRA, GOI, 2016; MACHADO, GOI, 2106).

\section{ESTUDO DE ESPAÇOS NÃO FORMAIS DE EDUCAÇÃO}

Quando da nova estruturação da matriz curricular, o segundo estágio (Cotidiano da Escola: Observação e Intervenção), realizado no quarto semestre do curso, precisou de algo que o diferenciasse do anterior, que é de mapeamento do espaço escolar. Considerava-se, contudo, prematuro fazer com que os licenciandos realizassem intervenções em sala de aula de Educação Básica estando ainda no quarto semestre do curso e não tendo ainda passado pelos estágios em que realizam monitorias ou em que organizam um GEO.

Tendo como ponto de partida esse contexto, propôs-se que o segundo estágio fosse realizado em espaços não formais de educação (biblioteca pública, museu de história e cultura, secretaria municipal de educação, comissão de educação da Câmara de Vereadores) ou em espaços onde se realiza uma educação não formal, mesmo que dentro da escola. Inclui-se, nesse caso, atividades como o dos Programas "Escola Aberta", "Mais Educação", "Implantação de Salas de Recursos Multifuncionais" etc.

Entende-se a educação não formal como um processo de formação de natureza complementar à educação formal, de duração variável, que pode acontecer tanto fora como dentro do sistema de ensino (escolas e universidades) e ser dirigido a pessoas de todas as idades. Compreende um conjunto de atividades ou programas que têm objetivos educacionais bem definidos sem se ater a uma sequência gradual. Os programas de educação não formal não conferem graus ou títulos, mas podem conceder certificados da aprendizagem obtida. A educação não formal não segue as normas e diretrizes estabelecidas pelos órgãos educacionais federais e estaduais, e não se orienta por uma legislação específica. É geralmente oferecida por instituições sociais governamentais e não governamentais, que buscam desenvolver nos indivíduos a formação de valores e competências para o trabalho, a inserção na cultura e o exercício da cidadania (BRASIL, 2016).

Transcreve-se a seguir dois de sete resumos dos artigos produzidos durante a oferta do estágio Cotidiano da Escola: observação e intervenção, no primeiro semestre de 2015, para ilustrar o que os acadêmicos constataram durante esse estágio. A primeira dupla realizou seu estágio conhecendo como funcionava o Programa de Salas de Recursos Multifuncionais em três escolas do município. 
pedagógicos, dispostos em espaço adequado e amparo de profissional habilitado a realizar atendimento especializado, tais fatores asseguram o pleno acesso e favorecem a permanência dos estudantes com necessidades educativas especiais nos sistemas de ensino. (DUPLA A).

A segunda dupla teve como objetivo conhecer as atividades realizadas através do "Programa Escola Aberta", em duas escolas do município.

\begin{abstract}
Percebemos que o objetivo do programa tem sido alcançado nas duas escolas. O envolvimento da comunidade nos projetos oferecidos pelo "Escola Aberta" nos faz perceber que o programa caminha na direção de alcançar o objetivo geral: contribuir para a melhoria da qualidade da educação, a inclusão social e a construção de uma cultura de paz, oferecendo aos alunos e à comunidade escolar um espaço aberto para a promoção da cidadania. (DUPLA B).
\end{abstract}

A maior parte dos acadêmicos sabia da existência dos programas devido sua inserção nas escolas durante o semestre anterior, mas não os conheciam em profundidade, surpreendendo-se com suas metas e com os valores aplicados pelo governo federal para sua execução. Vários foram os comentários sobre a enorme quantia aplicada na Educação Básica pelo governo federal, algo desconhecido para eles. As investigações mostraram que as próprias escolas não têm ideia da dimensão e alcance desses programas. Cada unidade escolar percebe apenas a sua comunidade e o seu entorno, não conseguindo vislumbrar o âmbito macroscópico dessas políticas.

As observações, análise e considerações dos acadêmicos em seus artigos atestam seu envolvimento na investigação, bem como sua atitude crítica em relação ao que constatam na realidade escolar, quando comparada ao que é proposto pelos programas do governo federal para a Educação Básica. Situação semelhante se verifica em relação ao segundo momento de investigação, em que os acadêmicos tiveram como tarefa investigar a contribuição dos espaços não formais para a educação no município. Reproduz-se a seguir excertos de dois artigos apresentados pelos licenciandos:

Este trabalho relata a elaboração do Plano Municipal de Educação 2015-2024 da cidade de Caçapava do Sul, que contou com a participação de uma comissão representante da Universidade Federal do Pampa (UNIPAMPA). Para elaboração das metas foram necessárias pesquisas em diversos setores relacionados à educação, a fim de propor estratégias que visem uma melhor qualidade de ensino. Observamos durante a elaboração deste plano que existe uma necessidade de buscar indicadores de educação para que sejam estabelecidas metas condizentes com a realidade do município. (DUPLA C).

O Ponto de Cultura, que iniciou suas atividades no ano de 2006, na cidade de Caçapava do Sul, está localizado no Centro de Tradições Gaúchas (CTG) Clareira da Mata, fundado em 1974. Em Caçapava do Sul, existem, atualmente, seis CTG e o que caracterizava seus frequentadores era sua classe social. Um dos fatores para a criação do Ponto de Cultura se deve às dificuldades encontradas pelos negros na sociedade. Eles eram descriminados por sua cor e origem, não the permitindo qualidade de moradia e emprego. O CTG Clareira da Mata, por ser para negros, proporcionou um espaço para que o Ponto de Cultura se instalasse. (...) As atividades são abertas ao público, sem distinção de raça, cor ou credo. Qualquer pessoa, que tiver vontade, pode se tornar um voluntário no Ponto de Cultura. Muitas pessoas, que fizeram cursos, conseguem administrar financeiramente sua família, mostrando que as atividades realizadas contribuem para uma melhora na vida familiar das pessoas. (DUPLA D). 
As atividades de estágio voltadas para o estudo da educação não formal empreendidas no município foram apresentadas durante as aulas presenciais e geraram discussões interessantes. Vários licenciandos não conheciam detalhes de como funcionam, por exemplo, a Biblioteca Pública Municipal, o Museu Histórico da cidade, e outras instituições de educação não formal. Comentários como "Não sabia que é assim [...]" foram frequentes, mostrando que pesquisas como essas suscitam a curiosidade dos acadêmicos e ampliam seu conhecimento sobre a própria cidade. Os estagiários constataram, por exemplo, que alguns programas tiveram redução ou corte da verba disponibilizada pelo poder público durante o ano de 2015, o que, em alguns casos, provocou sua precariedade ou cancelamento da oferta (Programa Escola Aberta, Programa Mais Educação).

O estudo sobre os espaços não formais de educação mostrou ainda que há muito por ser feito no município, que mantém de forma precária o museu e a biblioteca da cidade. Outros espaços, por falta de maior apoio do poder público (Ponto de Cultura, Secretaria Municipal de Educação) ou das instituições que os mantêm (SESC, SENAI), também funcionam aquém da sua potencialidade. Essa situação faz com que a população não tenha acesso fácil e contínuo à cultura letrada, histórica e/ou científica.

Essa forma de desenvolver o segundo componente curricular de estágio mostrou-se produtiva e enriquecedora em termos de conhecimento sobre a execução de políticas públicas. Além disso, o foco desse estágio sobre práticas educativas em espaços não formais de educação contribui para que os licenciandos percebam que existem outros espaços de profissionalização, além da escola de Educação Básica. Também para os professores do curso, além do aprendizado de como funcionam esses espaços, esse estágio contribui para chamar a atenção que os espaços não formais de educação necessitam ser mais bem estudados e atendidos por ações da universidade.

\section{PROBLEMAS ENCONTRADOS NA PRÁTICA PEDAGÓGICA DO ESTÁGIO}

Durante os dois primeiros semestres de estágio os licenciandos concentramse em realizar um reconhecimento dos espaços formais e não formais de educação e a fazer uma leitura crítica das condições de trabalho dos profissionais da área de educação. A partir do terceiro estágio, previsto para o quinto semestre do curso, os acadêmicos passam a ser desafiados a contribuir com soluções para problemas enfrentados pelos professores da Educação Básica com a aprendizagem de conteúdos pelos estudantes.

Durante o estágio denominado Cotidiano da Escola: Monitoria, os estagiários auxiliam os professores em sala de aula a desenvolver um projeto de resgate da aprendizagem por estudantes da Educação Básica de conteúdos de Física, Química ou Matemática.

Esse estágio, assim como os demais, sofreu alteração de foco desde que foi ofertado pela primeira vez, em 2012. Nas primeiras edições (2012, 2013 e 2014), os licenciandos deviam reunir-se na escola, em turno contrário às aulas, com alunos que estivessem com dificuldades de aprendizagem nas componentes da área específica em que pretendiam a titulação ${ }^{2}$ e promover aulas de reforço. A experiência mostrou que alguns estagiários se saiam bem nessa tarefa, especialmente os da área de Matemática, componente em que usualmente há 
vários estudantes com desempenho aquém do esperado. Outros estagiários, contudo, tinham dificuldades em reunir estudantes interessados nas aulas de reforço, e costumavam relatar, frustrados, que não conseguiam realizar o estágio conforme o previsto.

Aproveitando a mudança na matriz curricular do CCEL, os professores decidiram dar outro enfoque para esse estágio e, ao invés de aulas de reforço, foram pensadas atividades de monitoria por parte do estagiário em aulas do professor supervisor. Dentre as atividades desenvolvidas nesse estágio podemos destacar o desenvolvimento de aulas experimentais, a organização de grupos de estudos, desenvolvimento de conteúdos usando o laboratório de informática como ferramenta didática, vídeos aulas para auxiliar na compreensão dos conteúdos trabalhados, uso da história da Matemática para a compreensão dos conceitos científicos, resolução de questões do Exame Nacional de Ensino Médio (ENEM), resolução de situações-problema, construção de modelos atômicos e aplicação de jogos lúdicos no ensino de Ciências e Matemática.

As atividades de monitoria sinalizam que os professores em formação inicial conseguem aprofundar os pressupostos teóricos relacionados às metodologias aplicadas nos contextos de sala de aula. Isso é evidenciado ao analisar os relatórios de estágio em que os graduandos fazem um aprofundamento teórico das metodologias trabalhadas. Esse aspecto está no excerto abaixo retirado de um diário relacionado às reflexões sobre o estágio docente.

\footnotetext{
O estágio foi um momento em que busquei atrelar aspectos teóricos com aspectos práticos. Foi um momento em que tentei mesclar a teoria e a prática para que fosse possível apresentar bons resultados. E, sobretudo perceber a necessidade em assumir uma postura não só crítica, mas também reflexiva da nossa prática educativa diante da realidade e partir dela, para que possamos buscar uma educação e qualidade que é garantida em lei (ESTAGIÁRIO A)
}

Outro aspecto observado nos relatórios de estágio de monitoria está relacionado ao licenciando ter a oportunidade de investigar o ambiente escolar, reconhecendo as potencialidades e limites do sistema educacional. Também se torna possível, ao estagiário, fundamentar discussões a respeito do papel do professor nesse contexto.

Observa-se que quando o estudante em formação inicial está articulado com as atividades de sala de aula consegue refletir mais sobre a sua própria prática pedagógica e colocar-se no lugar do professor titular do componente curricular, o que no estágio de observação não é evidenciado, pois o graduando somente observa e registra o que acontece no contexto de sala de aula, mas não exercita a docência.

\section{INTERDISCIPLINARIDADE COMO PARTE DA PRÁTICA PEDAGÓGICA NO ESTÁGIO}

Até 2015, quando da oferta da componente Cotidiano da Escola: Grupo de Estudos Orientado, os estagiários eram orientados a produzir um projeto que aprofundasse um tópico da área específica em que obtém a titulação. Esse projeto deveria ser desenvolvido em turno contrário às aulas regulares dos alunos da Educação Básica, em espaço disponibilizado pelas escolas. Vários e excelentes 
estágios com esse objetivo. A título de exemplo, descrevemos brevemente sete GEO de Matemática, cada um deles criado por uma estagiária ${ }^{3}$.

Aplicabilidade da Matemática no Cotidiano: atividade desenvolvida com alunos do 1ㅇ e 20 Anos do Ensino Médio, com o objetivo de investigar o uso de conceitos matemáticos em situações cotidianas como atividades comerciais, de lazer e de trabalho na zona rural do município.

Jogos com Frações: o tema levou em conta a importância do estudo dos números racionais, devido a seu uso frequente em situações cotidianas. O GEO foi desenvolvido na forma de jogos com alunos de 1으 e 2을 Anos do Ensino Médio.

Jogos com Decimais: este estudo sobre cálculos com números decimais foi desenvolvido com alunos de 1ㅇ e 2을 Anos do Ensino Médio na forma de jogos.

História da Matemática: desenvolvido com alunos do 70 Ano do Ensino Fundamental, a produção final deste GEO foi a elaboração de uma maquete retratando o desenvolvimento do processo de contagem desde a pré-história até os tempos atuais.

Os remédios e a Matemática: este GEO foi desenvolvido adotando como proposta investigar o conteúdo matemático envolvido na fabricação e uso de remédios. Após selecionar textos que tratavam do assunto, o grupo criou um blog, apresentando o conteúdo na forma de problemas resolvidos e jogos.

O Uso de Mídias Tecnológicas para o Ensino-Aprendizagem de Funções: este GEO voltou-se para o estudo de como são construídos gráficos de funções lineares, quadráticas, exponenciais, logarítmicas e trigonométricas em planilhas eletrônicas e usando um software livre (Geogebra).

A Matemática no Corpo Humano: O objetivo do GEO foi investigar a validade das proporções do corpo humano apresentadas por Marcus Vitruvius Pollio (século I a. C.) e eternizada na imagem do Homem Vitruviano, em torno do ano de 1490, pelo estudo anatômico de Leonardo da Vinci. Foram realizados estudos sobre razão, proporção e o uso da regra de três simples.

Tal como ilustram alguns dos exemplos acima, vários dos GEO desenvolvidos durante o período de 2012 a 2014 ensaiavam propostas interdisciplinares, abrindo-se para o diálogo e a articulação com áreas de conhecimento diferente daquela em que o licenciando requeria sua titulação. Esse trabalho, contudo, era uma iniciativa isolada dos estagiários e fruto da sua formação durante a licenciatura, uma vez que cursavam componentes curriculares obrigatórias de áreas do conhecimento diferentes da titulação requerida. Esse movimento de diálogo com outras áreas de conhecimento por parte do licenciando, a partir de uma formação em que ele não se limita a cursar componentes de uma única área de formação, é descrito em Hartmann (2007). De acordo com a autora, quando o curso de formação:

(...) envolve a oportunidade de cursar disciplinas que não estão diretamente relacionadas à sua formação específica ou de disciplinas que são obrigatórias para alunos de diferentes cursos [isso favorece] a abertura do professor para questões que não dizem respeito apenas à disciplina específica com que ele [professor] trabalha. (p. 164). e colocar em prática atividades interdisciplinares, de modo a capacitar para a 
docência, passaram, a partir de 2015, a incentivá-los a desenvolver projetos interdisciplinares no componente curricular Seminário Integrado, do Ensino Médio, das escolas públicas estaduais gaúchas durante o estágio de GEO.

Esse componente, com uma carga horária de duas horas semanais de aula, foi instituído quando da reestruturação do Ensino Médio, no Estado do Rio Grande do Sul, em 2012, para um Ensino Médio Politécnico e de Educação Profissional Integrada. De acordo com o documento que traça as diretrizes para essa reestruturação:

O trabalho interdisciplinar, como estratégia metodológica, viabiliza o estudo de temáticas transversalizadas, o qual alia a teoria e prática, tendo sua concretude por meio de ações pedagógicas integradoras. Tem como objetivo, numa visão dialética, integrar as áreas de conhecimento e o mundo do trabalho. (RIO GRANDE DO SUL, 2011, p. 19).

A realização do estágio de GEO em aulas de Seminário Integrado, além de resolver (para os estagiários) o problema da reduzida participação de alunos da Educação Básica em atividades realizadas em turno contrário às aulas regulares, também atendeu uma necessidade dos professores responsáveis pelo componente curricular. Boa parte dos docentes da Educação Básica, especialmente os responsáveis por Seminário Integrado, não se sentia preparado e à vontade para desenvolver projetos interdisciplinares sobre temáticas transversais. A contribuição dos estagiários (e, por decorrência, do Curso de Licenciatura) foi fundamental para que os professores da Educação Básica constatassem a viabilidade da proposta interdisciplinar e a riqueza da experiência de conhecimento oportunizada aos estudantes.

O processo de elaboração e execução de atividades interdisciplinares contribui para capacitar os licenciandos a construir um conhecimento integrado do que estudam durante a graduação e a interagir entre si para a solução de situações que exigem uma ação coletiva, pois a interdisciplinaridade pressupõe que exista "um diálogo entre pares, capazes de compreender a mensagem das diferentes línguas nas suas entrelinhas" (FAZENDA, 2008, p. 14). Por outro lado, considera-se que à medida que o processo interdisciplinar acontece na escola, os alunos da Educação Básica também vão se tornando mais capazes de discutir questões complexas da atualidade.

Sendo um processo que precisa ser vivenciado, para ser assimilado em sua complexidade, a interdisciplinaridade ganha importância na vida escolar à medida que os docentes passam a desenvolver de forma integrada um trabalho pedagógico que capacita o estudante a comunicar-se, argumentar, enfrentar problemas de diferentes naturezas e a elaborar críticas ou propostas de ação em torno de questões abrangentes da atualidade (HARTMANN; ZIMMERMANN, 2007, p. 3).

Era frequente ouvir dos docentes depoimentos sobre a dificuldade de promover a interdisciplinaridade na escola devido à falta de conhecimento sobre como realizá-la na prática. Apesar do componente de Seminário Integrado ter sido criado para ser um espaço onde poderiam empreender atividades interdisciplinares, os docentes sentiam-se inseguros e vários preferiam aproveitar as aulas para reforçar o estudo sobre conteúdos que não conseguiam abordar em suas aulas por falta de tempo. 
A entrada dos estagiários no espaço pedagógico de Seminário Integrado tornou-se uma oportunidade de aprendizagem sobre a prática interdisciplinar tanto para os licenciandos como para os docentes da Educação Básica. Coube aos professores universitários acompanhar o planejamento e a implantação dos projetos. No entanto, observou-se que os estagiários sentiram dificuldades em promover um planejamento em parceira com os professores titulares da disciplina, visto que muitos usam o tempo do Seminário Integrado para trabalhar com os conteúdos de sua própria área e não promovem um trabalho interdisciplinar. Essa atitude dificulta o pensar interdisciplinarmente, pois o professor acaba trabalhando sozinho e não realiza trocas com os seus pares. Os estagiários observando isso trocam ideias no espaço acadêmico sobre a melhor forma de promover um trabalho interdisciplinar. São nesses momentos de reflexão que o professor universitário torna-se uma figura fundamental nesse processo, pois faz com que o estagiário perceba que o trabalho interdisciplinar exige conhecimento, troca e aprofundamento teórico de conteúdos sobre os quais não possui conhecimento.

O graduando, ao trabalhar em uma ação interdisciplinar, começa a perceber de que esse tipo de trabalho exige estudo, pois os estudantes da Educação Básica começam a fazer perguntas relacionadas a outras áreas do conhecimento e, muitas vezes, o professor não está preparado para respondê-la. É fundamental que o licenciando perceba que são nesses momentos que ele aprende com sua própria prática pedagógica, pois refletirá e aprofundará conhecimentos que vão além de sua formação.

As temáticas que envolveram os seminários integrados foram variadas. Alguns estagiários optaram por trabalhar com temáticas já aprofundadas em componentes curriculares da graduação, como Integração das Ciências. Eles alegam que sentem mais segurança em trabalhar com temas já discutidos em aulas de graduação e sobre o qual realizaram um aprofundamento teórico.

Observa-se no excerto a seguir a relevância de trabalhar com propostas interdisciplinares e do desafio em promover esse tipo de experiência, como também as dificuldades que os licenciandos sentem em romper com um currículo linear.

\begin{abstract}
No curso de Licenciatura em Ciências Exatas da UNIPAMPA, somos incentivados a realizar planejamentos e estudos que envolvam propostas interdisciplinares e abordagem de temas transversais. Projetos como este, normalmente não seguem a mesma ordem do currículo estudado nas escolas. Neste sentido, ficamos preocupados em estudar conteúdos que fossem do currículo do 10 ano do Ensino Médio, quando era preciso estudar outros conteúdos acabávamos tendo certo receio e não exigindo muito dos alunos. Este ainda é um desafio, superar esta cronologia que os conteúdos vêm sendo estudados nas escolas, pois a ordem dos conteúdos pode ser alterada conforme a necessidade dos projetos (LICENCIANDA B).
\end{abstract}

A experiência de trabalhar os estágios em Seminário Integrado, apesar das dificuldades apontadas, foi positiva. Os graduandos afirmam que é possível fazer um trabalho interdisciplinar na Educação Básica, porém não é algo trivial. Afirmam que é importante este tipo de proposta curricular ser realizada entre os pares, pois como afirma Fazenda (2008), um trabalho interdisciplinar exige articulação entre diferentes saberes. 
A partir do ano de 2017, o Seminário Integrado da rede do Estado do Rio Grande do Sul foi extinto. Com isso o Estágio: Cotidiano da Escola - GEO passou a ser implementado em turmas da Educação Básica que desenvolvem um trabalho mais voltado para a pesquisa.

No segundo semestre de 2017 foram implementados seis (6) estágios de GEO em turmas da Educação Básica nas disciplinas de Matemática, Química e Física. Entre as atividades desenvolvidas estão projetos sobre os jogos lúdicos; Matemática Financeira e Experimentação no Ensino de Ciências. Observa-se que as atividades trabalhadas foram diferentes daquelas desenvolvidas no Seminário Integrado, pois esse componente curricular era voltado para a pesquisa no contexto escolar. Com isso, percebe-se uma perda, das escolas públicas do Rio Grande do Sul, de um espaço e tempo para trabalhar com a pesquisa em sala de aula.

Outro fator observado nas reflexões realizadas com os estagiários está relacionado à relevância em desenvolver temas de acordo com os contextos dos indivíduos. Essa reflexão é registrada na fala da licencianda $B$, que destaca a importância de trabalhar temáticas do cotidiano dos estudantes.

Os resultados positivos da implementação desta proposta e os desafios enfrentados sinalizam a necessidade de elaboração e implementação de outras temáticas que estejam diretamente relacionadas ao cotidiano dos alunos, auxiliando na compreensão de suas realidades (LICENCIANDA B)

\section{A DOCÊNCIA COMO PRÁTICA PEDAGÓGICA}

Nos estágios Cotidiano da Escola: Regência I e Cotidiano da Escola: Regência II, previstos para o sétimo e oitavo semestre, os licenciandos exercitam efetivamente à docência, de forma individual e autônoma, em sala de aula, para uma turma dos Anos Finais do Ensino Fundamental ou do Ensino Médio. A regência no Ensino Fundamental é realizada pelos licenciandos que pretendem a titulação como professores de Matemática ou Ciências. O estágio de regência é realizado no Ensino Médio pelos que concluirão o curso como professores de Física, Matemática ou Química.

São previstas 80 horas de atividades nesses dois estágios, sendo quatro horas para reconhecimento da turma e observação do trabalho, verificação do que o professor vem fazendo com a turma, e 24 horas de aula para a regência propriamente dita.

Nos Seminários de Estágio, que acontecem no final de cada semestre e durante os quais os licenciandos relatam suas experiências, torna-se claro para os docentes do curso que a regência é uma vivência ímpar para os acadêmicos. Apesar de a sala de aula não representar mais novidade, devido às experiências vivenciadas nos estágios anteriores, estar frente a frente de uma turma, faz com que eles se deparem com situações que representam novos aprendizados do exercício da docência. Sintetiza-se a seguir, alguns dos aprendizados relatados pelos licenciandos durante os Seminários de Estágio realizados semestralmente no CCEL:

Aprendizagem do conteúdo a ser ensinado: mesmo estando praticamente no final do curso, os estagiários relatam que aprendem muito do conteúdo da sua 
área de profissionalização ao preparar as aulas que irão desenvolver na Educação Básica. Ensinar algo é uma tarefa que exige domínio do conteúdo a ser ensinado. Esse domínio, durante o curso, é usualmente testado em provas escritas, relatórios ou outras atividades, mas como para ser aprovado basta um percentual de $60 \%$ de acerto, é certo que muito conhecimento fica sem ser assimilado plenamente ou mesmo esquecido após o término do semestre. Nesse caso, a aprendizagem acontece, efetivamente, quando o licenciando precisa explicá-lo para uma turma de alunos. Aí, ele é confrontado com detalhes que não havia se perguntado ou dúvidas que não havia esclarecido previamente.

O conteúdo aprendido no curso auxilia a compreender o conteúdo escolar: os estagiários relatam que o conteúdo aprendido durante o curso é bastante mais aprofundado (e segue percursos não explorados na Educação Básica), mas que o empenho em compreender contribui para desenvolver o raciocínio, tornando de fácil a compreensão dos conteúdos a serem ensinados na Educação Básica.

A parte pedagógica ocupa bastante tempo do trabalho de um professor: os estagiários aprendem que, efetivamente, ser professor não se resume a entrar em sala de aula e ministrar aulas. É necessário planejar as aulas, preparar material manipulável (no caso da Matemática) ou experimentos (no caso da Física e Química) e acompanhar por meio de avaliações formativas se os estudantes acompanham e aprendem o conteúdo estudado.

Ensinar menos e melhor: os estagiários aprendem que não adianta pretender que os alunos aprendam grandes quantidades de conteúdo em um curto espaço de tempo. A aprendizagem é algo que vai acontecendo aos poucos, à medida que os conteúdos vão sendo retomados em maior profundidade. Nesse sentido, os licenciandos aprendem que a aprendizagem precisa ser significativa para os estudantes. De acordo com a teoria de aprendizagem significativa de Ausubel, os conteúdos a serem aprendidos necessitam estar relacionados de forma substantiva e não arbitrária ao que o aprendiz já sabe. Assim, para que ocorra uma aprendizagem significativa, é necessário que o aprendiz tenha subsunçores adequados em sua estrutura cognitiva para receber a nova informação e incorporá-la aos seus saberes (MOREIRA, 1999).

Desenvolvimento de estratégias diferenciadas de ensino: os estagiários são orientados a elaborar atividades diferenciadas de ensino e a não se ater à tradicional aula expositivo-dialogada, usando apenas como tecnologia o quadro brando e pinceis para apresentar o conteúdo a ser aprendido. Esse é um esforço extraordinário que muitos professores deixam de lançar mão devido ao pouco tempo que possuem para preparar suas aulas, mas do qual os estagiários não são dispensados. Eles aprendem que existe um leque de possibilidades metodológicas e tecnológicas para promover uma aula.

Despertar a curiosidade dos alunos: os licenciandos logo comprovam que o interesse do aluno por determinado conteúdo torna-se um forte impulso para a aprendizagem. É necessário instigar o aluno para investigar o conteúdo desconhecido e não apresentá-lo pronto e acabado, destruindo toda a possível curiosidade do estudante.

Aproximar-se dos estudantes durante as aulas: a preocupação com o aprendizado aproxima o professor do aluno. Os estagiários relatam que perguntar ao aluno, aparentemente distraído ou apático, sobre sua compreensão do que está sendo explicado, faz com que o estudante perceba uma real preocupação do 
professor para com ele e o faz, em boa parte das vezes, mudar de uma atitude passiva em aula para uma atitude participativa.

Ser professor educador: mais do que apenas ensinar conteúdos, o professor é alguém que se preocupa com o bem-estar e o futuro do aluno, com a formação de pessoas comprometidas, éticas e capazes de atuar crítica e participativamente frente a situações cotidianas. $O$ docente é, portanto, mais do que um professor, um educador (COSTA, 2001).

\section{CONSIDERAÇÕES FINAIS}

Os estágios em uma licenciatura apresentam, de modo geral, uma característica semelhante, que é a de capacitar os futuros professores para a prática pedagógica através do exercício da regência em aulas da Educação Básica. Essa característica central e fundamental da formação docente está presente nos dois últimos semestres de estágio do CCEL. Porém, entendemos que o licenciando necessita, além de um espaço em que exercite o domínio de classe e de conteúdo de forma autônoma, de uma formação que o capacite para o trabalho coletivo e interdisciplinar, permeado por diferentes situações-problema que o desafiem diariamente.

O CCEL, porém, apresenta particularidades devidas ao desafio de, em único curso, oferecer uma formação que seja, ao mesmo tempo, específica para uma área (Física, Química, Matemática ou Ciências Naturais) sem limitar as possibilidades de o licenciando dedicar seu estudo também a outra. Iniciar o estágio no terceiro semestre representa outro desafio, pois é preciso prever a possibilidade de o licenciando decidir trocar a escolha da área de formação em que obterá a titulação.

Uma possível implicação desse estudo na formação inicial de professores seria a de investigar como os estágios que estão sendo desenvolvidos no decorrer do curso de graduação são mais favoráveis comparados aos estágios que são desenvolvidos apenas nos dois últimos semestres do curso de graduação. Ao desenvolver uma agenda de discussão próxima aos problemas que surgem durante o estágio de docência acreditamos que possa haver uma percepção mais positiva de ajuda vinda dos programas para a formação inicial. No entanto, outras pesquisas precisam ser realizadas para embasar os aspectos levantados neste estudo. 


\title{
The internship in the context of teacher training: field of experimentation and reflection on pedagogical practice
}

\begin{abstract}
The results of the research on the experience of introducing the teaching internship in the course of Exact Sciences - Licenciatura, of the Federal University of Pampa (UNIPAMPA), Campus Caçapava do Sul / RS, are reported as of the third semester of the Course. In this perspective, the internship format assumes the characteristic of being an interdisciplinary space that allows the graduate to know the professional environment through didacticpedagogical activities of observation, problematization and reflection of the teaching practice. The question that leads to the discussion is: In what ways did the changes introduced in the stages improve the training of academics and demand new challenges for the teaching staff? To do so, we analyze the internship practices implemented from the change in the Pedagogical Project of the Course. There are favorable results for the teaching practice to occur from the first years of graduation, as an action integrated with other curricular components and not just as a pedagogical complement at the end of the graduation.
\end{abstract}

KEYWORDS: Teaching internship. Pedagogical practice. Teacher training. Graduation. 


\section{NOTAS}

1 Este trabalho recebeu o prêmio de melhor pesquisa, na categoria Ciências Humanas, durante o VII Salão Internacional de Ensino, Pesquisa e Extensão (SIEPE), da Universidade Federal do Pampa. Disponível em: <http://eventos.unipampa.edu.br/siepe/>. (VIVIAN; HARTMANN; VIVIAN, 2015).

20 Curso de Ciências Exatas - Licenciatura possibilita ao graduando escolher em qual das seguintes áreas pretende diplomar-se: Ciências Naturais, Física, Matemática ou Química (UNIPAMPA, 2015).

3 Maiores detalhes sobre a criação desses GEO são descritos no trabalho de HARTMANN (2014), disponível em:<http://w3.ufsm.br/ceem/eiemat/Anais/arquivos/ed_4/CC/CC_Hartmann_Angela.pdf $>$ acesso em 04 de janeiro de 2018.

\section{REFERÊNCIAS}

ANDRADE, R. C. R.; RESENDE, M. R. Aspectos Legais do Estágio na Formação de Professores: uma retrospectiva histórica. Educação em Perspectiva. Viçosa, v. 1, n. 2, p. 230-252, jul/dez. 2010.

AZAMBUJA, C. D. ; GOI, M. E. J. ; HARTMANN, A. M. . A Formação Docente em Química e as Práticas Pedagógicas dos professores da Educação Básica. In:

SINTEC-Seminário Internacional de Educação em Ciências, 2014, Rio Grande. SINTEC 3- Seminário Internacional de Educação em Ciências. Rio Grande: FURG, 2014.

BIANCHETTI, L. O processo da escrita: elementos inibidores e facilitadores. In: BIANCHETTI, L.; MEKSENAS, P. (orgs.). A trama do conhecimento: teoria, método e escrita em ci6encia e pesquisa. 2. ed. Campinas, SP: Papirus, 2012.

BRASIL. INSTITUTO NACIONAL DE ESTUDOS E PESQUISAS EDUCACIONAIS ANÍSIO TEIXEIRA (INEP). Educação formal - Educação não-formal. Disponível em: $<$ http://pergamum.inep.gov.br/pergamum/biblioteca/pesquisa thesauro.php?re solution2=1024 1>. Acesso em: 23 jan. 2016.

BRASIL. Lei de Diretrizes e Bases da Educação Nacional. Lei número 9394, 20 dez.1996.

BRASIL. Parecer CNE/CP 009/2001: Diretrizes curriculares nacionais para a formação inicial de professores da educação básica, em nível superior, curso de licenciatura, de graduação plena. Brasília: MEC / CNE, 2001. Disponível em: <http://www.mec.gov.br/cne/ftp/PNCP/CNCP009.doc>. 
Encontro de debates sobre o Ensino de Química, 2016, Pelotas. 36 EDEQEncontro de debates sobre o Ensino de Química, 2016.

BRITZMAN, D. P. Practicemakespractice: A criticalstudyoflearningtoteach. Albany: StateUniversityof New York Press, 1991

CAIRES, S.; ALMEIDA, L. S. Possíveis contributos do estágio para o desenvolvimento vocacional: estudo com alunos universitários. Psychologica, 26, 187-198, 2001.

CAPEL, S., LEASK, M.; TURNER, T. Startingtoteach in thesecondaryschool: A companion for thenewlyqualifiedteacher. London and New York: Routledge, 1997.

CAPORALE, G. PIBID - Espaço de formação docente: uma análise das entre a escola Básica e Universidade.2015, 120f. Dissertação (mestrado em Educação) Faculdade de Educação da Universidade Federal do Rio Grande do Sul, Porto alegre, 2015.

CARVALHO, A. M. P. de. Os Estágios nos Cursos de Licenciatura. São Paulo: Cengage Learning, 2012. Coleção Ideias em Ação.

Costa, A. G. da. O professor como educador: um resgate necessário e urgente. Salvador: Fundação Luís Eduardo Magalhães, 2001. 180 p.

DEMO, P. Professor do futuro e reconstrução do conhecimento. Petrópolis: Vozes, 2004.

CONRADO, G. D. R.; GOI, M. E. J. Reconhecendo elementos da prática docente de professores das ciências exatas e matemática da educação básica. In: III Congresso Internacional de Educação Científica e Tecnológica, 2015, Santo Ângelo. III CIECITEC, 2015.

DEMO, P. Educar pela pesquisa. 8. ed. Campinas: Autores Associados, 2007.

DEMO, P. Pesquisa e reconstrução do conhecimento: metodologia científica no caminho de Habermas. Rio de Janeiro: Tempo Brasileiro, 2009.

FAZENDA, I. C. A. (Org.). O que é interdisciplinaridade. São Paulo: Cortez, 2008. 
GOI, M. E. J.; AZAMBUJA, C. D. O estágio em Química como ferramenta para areflexão da Prática docente: relato de experiência. In: EDEQ- Encontro de Debates de Ensino de Química, 2014, Santa Cruz do Sul. 340 EDEQ Inovação no Ensino de Química: Metodologias. interdisciplinariedade e Politecnia, 2014.

HARTMANN, A. M.. Estágio Docente em Matemática: inovar exige criatividade. In: 4a Escola de Inverno de Educação Matemática 20 Encontro Nacional PIBIDMatemática, 2014, Santa Maria, RS. Anais da 4a Escola de Inverno de Educação Matemática 20 Encontro Nacional PIBID-Matemática. Santa Maria, RS: UFSM, 2014. v. 2. p. 1-8.

HARTMANN, A. M.; ZIMMERMANN, E. O trabalho interdisciplinar no Ensino Médio: A reaproximação das "Duas Culturas". Revista Brasileira de Pesquisa em Educação em Ciências, v. 7, n. 2, 2007.

HARTMANN, A. M. Desafios e possibilidades da Interdisciplinaridade no Ensino Médio. 2007, 229f. Dissertação (Mestrado em Educação). Faculdade de Educação da Universidade de Brasília. Brasília, 2007.

HIRATA, J. M. ; GOI, M. E. J. Estágio de Observação: Reflexão sobre aspectos da prática pedagógica. In: XIII Encontro sobre Investigação na Escola, 2015. XIII Encontro sobre Investigação na Escola, Erechim, 2015.

MACHADO, C. G. Tornar-se professor - da idealização à realidade. Tese (Doutorado em Psicologia Educacional). Évora: Universidade de Évora Departamento de Pedagogia e Educação, 1996.

MACHADO, A. V. ; GOI, M. E. J. . Análise de Eixos Educacionais a partir da observação das aulas na Educação Básica. In: 360 EDEQ, 2016, Pelotas. 360 EDEQ Encontro de Debates do Ensino de Química, 2016. p. 238-245.

MOREIRA, M. A. Teorias da Aprendizagem. São Paulo: EPU, 1999.

PIMENTA. S. G.; LIMA, M. S. L. Estágio e docência: diferentes concepções. Revista Poíses. V.3, n.3-4., p. 5-24, 2005, 2006.

RIO GRANDE DO SUL. Proposta Pedagógica para o ensino médio politécnico e educação profissional integrada ao ensino médio-2011-2014. Secretaria da Educação. Porto Alegre. Out./Nov. 2011. 
MANCUSO, R. Aprender em Rede na Educação em Ciências. Ijuí: Unijuí, 2008. p. 207-220.

SANTOS, F. M. T.; PASSOS, C. G. Formação Docente no Curso de Licenciatura em Química da UFRGS: estratégias e perspectivas. In: XIV Encontro Nacional de Ensino de Química. Curitiba, 2008.

SIMÕES, C. O desenvolvimento do professor e a construção do conhecimento pedagógico. Aveiro: Fundação João Jacinto de Magalhães, 1996.

UNIPAMPA. Projeto Político Pedagógico do Curso de Licenciatura em Ciências Exatas. Caçapava do Sul: UNIPAMPA, 2014. Disponível em:

<http://cursos.unipampa.edu.br/cursos/cienciasexatas/ppc-do-curso/>. Acesso em: 19 jun. 2015.

VIVIAN, C. F. ; VIVIAN, M. F. ; GOI, M. E. J. . Estágio de Observação: um momento de pesquisa e reflexão sobre o ambiente e a dinâmica escolar. In: XVII Seminário Internacional de Educação do Mercosul, 2015, Cruz Alta. XVII Seminário Internacional de Educação do Mercosul, 2015.

VIVIAN, C. F.; HARTAMNN, A. M. VIVIAN, M. F. O programa de implantação de salas de recursos multifuncionais em escolas de Caçapava do Sul, In: VII Salão Internacional de Pesquisa, ensino e Extensão, Alegrete, 2015. 
Recebido: 2018-02-21

Aprovado: 2019-03-09

DOI: $10.3895 /$ rbect.v12n2.7877

Como citar: HARTMANN, A. M.; GOI, M. E. J. O estágio no contexto da formação de professores: campo de experimentação e reflexão sobre a prática pedagógica. Revista Brasileira de Ensino de Ciência e Tecnologia, v. 12, n. 2, 2019. Disponível em: <https://periodicos.utfpr.edu.br/rbect/article/view/7877>. Acesso em: xxx. Correspondência: Mara Elisângela Jappe Goi - maragoi28@gmail.com Direito autoral: Este artigo está licenciado sob os termos da Licença Creative Commons-Atribuição 4.0 Internacional. 